\title{
Predicting the Concentration Characteristics of Itakpe Iron Ore for cut-off Grade Estimation
}

\section{${ }^{* 1}$ NWOSU JOSEPH IFEANYI; KINGSLEY OKENGWU; ALIMI ADESOJI}

\author{
${ }^{I}$ Department Of Geology, ${ }^{2}$ Department Of Mathematics and Statistics, University Of Port Harcourt, PMB 5323, Nigeria.
}

\begin{abstract}
Concentration characteristics of an ore are very critical to the estimation of cut-off grade of a deposit. A mathematical model that can lead to their quick prediction will significantly enhance ore reserve estimation, mine planning and the economy of the mining venture as a whole. In this paper attempts have been made to establish a functional relationship between ore grades and concentration characteristics of Itakpe Iron ore. The Wilcoxon signed rank test has been used to establish a significant level of correspondence between actual values and values obtained from the model. The model has shown that the performance characteristics of the processing plant and the grade of the ore both play vital roles in deciding the concentration characteristics of an ore. $\odot$ JASEM
\end{abstract}

\section{DOI: http://dx.doi.org/10.4314/jasem.v17i2.14}

Itakpe iron ore deposit is a magnetite-hematite mineralization consisting of 14 ore layers of economic value ranging in grade predominantly from $14.8 \% \mathrm{Fe}$ to $41 \% \mathrm{Fe}$ with an overall average grade of $36 \% \mathrm{Fe}$ (NIOMC Project Report; 1980, Vol. 2). It is located in Latitude $07^{\circ} 36^{\prime} 20^{\prime \prime} \mathrm{N}$ and Longitude $6^{\circ} 18$ '35" E in Okehi Local Government Area of Kogi state, Nigeria (fig 1). Exploitation is by open-pit mining method, and so far, two production benches are being advanced. The iron ore is currently being processed using magnetic and gravity methods of mineral processing; and flotation plant is being constructed for future beneficiation of the iron ore. Because of the multiple grades and constantly changing cost of production and price of iron ore in the mineral market, there is constantly the need to reevaluate the cut-off grade of Itakpe deposit. In doing this, there arises the need for huge operational expenses on laboratory analysis to establish concentration characteristics of Itakpe ore.

Thus, the significant impact of predicting concentration characteristics of an ore like tailings grade and recovery on the economies of mining outfits cannot be over - emphasized given the enormous financial cost of laboratory analysis and time required for such analysis to be ready for onward utilization in cut-off grade assessment. Hence, various experts have attempted to establish if there is a functional relationship between ore grade (feed grade) and concentration characteristics like recovery, yield, and tailings grade which are essential variables in cut - off grade estimation. If such relationship exists, this would enable experts predict future values of such characteristics based on production history of the deposits or analogous deposits.

It has been documented by various authors after a detailed analysis of Chalchedan iron ore that no such relationship exists (Promerantsev, 1990). However, Agabalian (1994), attempted to disprove this assertion by showing a relationship between ore grade and tailings grade, and between ore grade and recovery, at Abovansky open-pit iron mine. He however, recognized the impact of plant efficiency in mineral recovery. The essence of this research is to attempt the verification of a relationship (if any) between ore grades and tailings grade and between ore grade and recovery at Itakpe, using historic concentration characteristics of Itakpe ores.

\section{MATERIALS AND METHOD}

The approach in predicting the cut - off grade of Itakpe deposit is to establish the relationship between ore grade and various concentration characteristics like tailings grade and metallurgical recovery; which can be utilized in predicting the cut - off grades for the prevailing production costs and values of ores.

To predict the concentration characteristics of Itakpe ore, statistical data of these characteristics for different grade have been gathered over time from Itakpe mine.

The Least Squares Method is used to analyze the above data with a view to establishing a functional relationship between them. The Least Squares Method is a mathematical tool that is used to provide a "best fit" equation to a series of data points in the sense that it is founded on the relationship that the sum of the squares of the differences between the actual data points and the points calculated for the "best fit" straight line has a minimum value; Donohue (1983) . Consequently the square of the deviation of the "best fit" equation $P\left(x_{i}\right)$ from the actual data points can be calculated as 


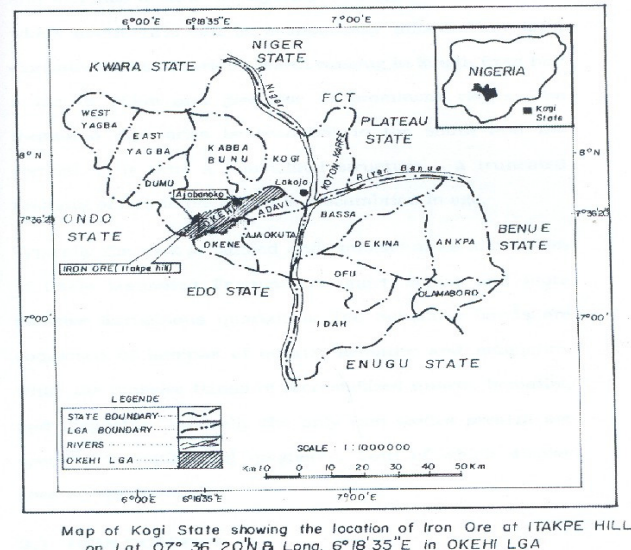

Fig. 1: Map of Kogi State Showing Location of Itakpe Hill

Table 1 Historic concentration characteristics of Itakpe ore 1988 - 1997

\begin{tabular}{|l|l|l|l|l|l|l|l|l|l|l|}
\hline & 1988 & 1989 & 1990 & 1991 & 1992 & 1993 & 1994 & 1995 & 1996 & 1997 \\
$\begin{array}{l}\text { Yonc. } \\
\text { Characteristics }\end{array}$ & & & & & & & & & & \\
\hline
\end{tabular}

Sources: Annual Report of Mines Laboratory Unity NIOMCO 1998 - 1997

$\boldsymbol{\sigma}$

$=$

$\sum_{i=1}^{n}\left[y_{i}-P\left(x_{i}\right)\right]^{2} \quad \rightarrow \quad \min$

Where

$y_{i}$ is the value of the given data at point $\partial \sigma / \partial a_{0}=$

$P\left(x_{i}\right)$, the Best fit equation which can be represented as:

$\sum_{i=}^{10}$
And

$$
\begin{gathered}
P\left(x_{i}\right)= \\
a_{0}+a_{i} x_{i}
\end{gathered}
$$

Where $a_{0}$ and the $a_{1}$ are constants, which depend on the efficiency of the processing plant and nature of ores and while $x_{i}$, represents the feed grade at point i. For a sample size of 10 we have,

$\sigma$

$$
\sum_{i=1}^{10}\left[y_{i}-\left(a_{n}+a_{1} x_{i}\right)\right]^{2} \rightarrow \min
$$

The values of the constants $a_{0}$ and $a_{1}$ can be found in such a way that a minimum deviation of "best fit" equation from the actual data points is obtained. This can be obtained by differentiating partially first with respect to $a_{0}$ and later, with respect to $a_{1}$ and equating both expressions to zero. So that

$$
\begin{aligned}
& \partial \sigma / \partial \alpha_{1}= \\
& \sum_{i=1}^{10}\left[y_{i}-\left(a_{0}+a_{1} x_{i}\right) x_{i}\right]
\end{aligned}
$$

Opening the brackets yields,

$$
\sum_{i=1}^{10} y_{i}=10 a_{0}+a_{1} \sum_{i=1}^{10} x_{i}
$$

$\sum_{1}^{10}: x_{2} y_{l}=$

$a_{0} \sum_{i=1}^{0} x_{i}+a_{1} \sum_{i=1} x_{i}^{2}$

$: 7$ 
Table 2: Calculation of variables in the least squares method for tailings grade prediction

\begin{tabular}{|l|l|l|l|l|}
\hline No. & $x_{i}$ & $y_{i}$ & $x_{i} y_{i}$ & $x_{i}{ }^{2}$ \\
\hline 1. & 40.95 & 12.85 & 526.21 & 1676.91 \\
\hline 2. & 38.68 & 12.30 & 475.76 & 1496.14 \\
\hline 3. & 37.88 & 12.10 & 458.35 & 1434.89 \\
\hline 4. & 37.03 & 11.91 & 441.03 & 1371.22 \\
\hline 5. & 36.45 & 11.77 & 429.02 & 1328.61 \\
\hline 6. & 36.44 & 11.75 & 428.17 & 1327.87 \\
\hline 7. & 35.01 & 11.42 & 399.81 & 1225.70 \\
\hline 8. & 34.95 & 11.41 & 398.77 & 1221.50 \\
\hline 9. & 34.42 & 11.28 & 388.26 & 1184.74 \\
\hline 10. & 34.19 & 11.22 & 383.62 & 1168.95 \\
\hline & $\mathbf{1 0}$ & $\sum_{i=1}^{10}$ & $\sum_{i}^{10}$ & 10 \\
& $\sum_{i=1}^{10} x_{i}=1$ & $\sum_{i=1} x_{i}=$ & $\sum x_{i}^{2}=13$ \\
\hline
\end{tabular}

In order to establish a relationship between tailings grade and feed grade, the variables in the above equations are calculated as in Table 2 using the data in Table 1 where:

$x_{i} \rightarrow$ Represents feed grade at various data points

$y_{i} \rightarrow$ Represents tailings grade at various data points

$n \rightarrow$ Number of data points.

Substituting in equations $6 \& 7$ yields

$$
\begin{aligned}
& 118=10 a_{0}+366 a_{1} \\
& 4329=366 a_{n}+13436.53 a_{1}
\end{aligned}
$$

Hence

$$
\begin{array}{lll}
10 a_{0}+366 a_{1}=0 & \ldots & \text { (i) } \\
366 a_{0}+13436.53 a_{1}=4329 & \ldots & \text { (ii) }
\end{array}
$$

Resolving into a matrix equation we have

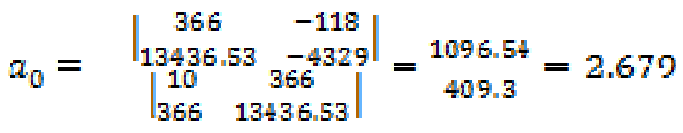

Hence $a_{0}=2.679$

$$
\frac{-\left|\begin{array}{cc}
10 & -118 \\
366 & -4329
\end{array}\right|}{\left|\begin{array}{cc}
10 & 366 \\
366 & 13436.59
\end{array}\right|}=\frac{-(-102)}{40.913=}=0.249
$$

Consequently

$$
P\left(x_{i}\right)=2.679+0.249 x_{i}
$$

... 9

$$
\text { Or } T_{g}=2.679+0.249 F_{g}
$$

Similarly, in establishing a relationship between metallurgical recovery $R_{m}$ and feed grade $F_{g}$ the variables in the equation will have to be calculated. In this case;

$x_{i} \rightarrow$ Represents feed grade at various data points

$y_{i} \rightarrow$ Represents metallurgical recovery

$n \rightarrow$ Number of data points (10).

Table 3: Calculation of variables in least squares method for metallurgical recovery prediction.

\begin{tabular}{|l|l|l|l|l|}
\hline $\mathrm{N}$ & $x_{i}$ & $y_{i}$ & $\mathrm{x}_{\mathrm{i}} y_{i}$ & $\boldsymbol{x}_{i}{ }^{2}$ \\
\hline 1. & 40.95 & 85.7 & 3509.4 & 1676.9 \\
\hline 2. & 38.68 & 84.3 & 3260.7 & 1496.1 \\
\hline 3. & 37.88 & 83.8 & 3174.3 & 1434.89 \\
\hline 4. & 37.03 & 82.6 & 3058.7 & 1371.22 \\
\hline 5. & 36.45 & 82.1 & 2992.55 & 1328.6 \\
\hline 6. & 36.44 & 82.9 & 3020.9 & 1327.8 \\
\hline 7. & 35.01 & 81.88 & 2866.7 & 1225.7 \\
\hline 8 & 34.95 & 81.83 & 2859.0 & 1221.5 \\
\hline 9. & 34.42 & 83 & 2856.86 & 1184.74 \\
\hline 10. & 34.19 & 81.3 & 2779.65 & 1169.0 \\
\hline & $\sum_{i=1}^{10} x_{i}=\mathbf{3 6 6}$ & $\sum_{i=1}^{10} y_{i}=\mathbf{8 2 9 . 4 1}$ & $\sum_{i=1}^{10} x_{i} y_{i}=30378.85$ & $\sum_{x_{i}{ }^{2}-13436.53}^{10}$ \\
& & & & $\sum_{i=1}$ \\
& & & & \\
\hline
\end{tabular}


As previously done, substituting the values of the variables in equation $6 \& 7$ we have

$$
\begin{gathered}
10 a_{0}+366 a_{1}=829.41 \\
366 a_{0}+13436.53 a_{1}=30378.85
\end{gathered}
$$

Again resolving into a matrix equation we have:

So that,

$$
\begin{gathered}
a_{0}=\frac{\left|\begin{array}{cc}
366 & -829.41 \\
13436.53 & 13436.53
\end{array}\right|}{\left|\begin{array}{cc}
10 & 366 \\
366 & 12107.84
\end{array}\right|}=\frac{25733.2473}{409.3}=62.871 \\
a_{1}=-\frac{\left|\begin{array}{cc}
10 & -829.41 \\
366 & -30378.85
\end{array}\right|}{\left|\begin{array}{cc}
10 & 366 \\
366 & 13436.53
\end{array}\right|}=\frac{-303786.5-(-303564.1)}{134365.3-133956}=0.548
\end{gathered}
$$

$$
\begin{gathered}
P\left(x_{i}\right)=62.871+0.548 x_{i} \\
\text { Or } R_{m}=62.871+0.548 F_{g}
\end{gathered}
$$

We now compare the actual values with the values computed from the model applied. We do this first for the tailings grade and then for the metallurgical recovery. In both cases using the Wilcoxon Signed Ranked Test (A.I.Arua et al 1997). For this test in both cases the hypotheses are:

\section{$H_{0}$ :The model values do not vary significantly from the actual values.}

$$
H_{1}: \text { The modei values do vary significantly from the actual values. }
$$

Table 4: Comparison of the tailings grade values

\begin{tabular}{|l|l|l|l|l|l|l|l|l|l|l|}
\hline & \multicolumn{9}{|c|}{ Year Of Production } \\
\hline & 1988 & 1989 & 1990 & 1991 & 1992 & 1993 & 1994 & 1995 & 1996 & 1997 \\
\hline $\begin{array}{l}\text { Actual } \\
\text { Value }\end{array}$ & 12.85 & 12.30 & 12.10 & 11.91 & 11.77 & 11.75 & 11.42 & 11.41 & 11.28 & 11.22 \\
\hline $\begin{array}{l}\text { Computed } \\
\text { Value }\end{array}$ & 12.88 & 12.31 & 12.11 & 11.75 & 11.76 & 11.75 & 11.40 & 11.38 & 11.25 & 11.19 \\
\hline$D_{\text {i }}$ (difference) & -0.03 & -0.01 & -0.01 & 0.16 & 0.01 & 0.00 & 0.02 & 0.03 & 0.03 & 0.03 \\
\hline Rank & 6.5 & 2 & 2 & 9 & 2 & & 4 & 6.5 & 6.5 & 6.5 \\
\hline +Rank & & & & 9 & 2 & & 4 & 6.5 & 6.5 & 6.5 \\
\hline -Rank & 2 & 2 & 2 & & & & & & & \\
\hline
\end{tabular}

Sum of positive rank $=T_{+}=34.5$

\begin{tabular}{|c|c|c|c|c|c|c|c|c|c|c|}
\hline & \multicolumn{10}{|c|}{ Year Of Production } \\
\hline $\begin{array}{l}\text { Metallurgical } \\
\text { Recovery }\end{array}$ & 1988 & 1989 & 1990 & 1991 & 1992 & 1993 & 1994 & 1995 & 1996 & 1997 \\
\hline $\begin{array}{l}\text { Actual } \\
\text { Value }\end{array}$ & 85.70 & 84.30 & 82.90 & 82.10 & 82.10 & 82.90 & 81.88 & 81.83 & 83.83 & 81.30 \\
\hline $\begin{array}{l}\text { Computed } \\
\text { Value } \\
\end{array}$ & 85.31 & 84.07 & 83.63 & 82.84 & 82.85 & 82.84 & 82.06 & 82.02 & 81.73 & 81.61 \\
\hline$D_{i}$ (differame) & 0.39 & 0.23 & -0.73 & -0.74 & -0.75 & 0.06 & -0.18 & -0.19 & 1.27 & -0.31 \\
\hline Rank & 6 & 4 & 7 & 8 & 9 & 1 & 2 & 3 & 10 & 5 \\
\hline +Rank & 6 & 4 & & & & 1 & & & 10 & \\
\hline -Rank & & & 7 & 8 & 9 & & 2 & 3 & & 5 \\
\hline
\end{tabular}

Sum of negative rank $=T_{-}=10.5$

Hence $T=10.5$ since it is the smallest of the two values.

For level of significane $(a=0.05)$, Wilconon s table value is $t=6$. Since $(T>t)$ we conclude that both sets of values do not vary significantly from each other.

Table 5: Comparison of the metallurgical recovery values 
Sum of positive rank $=T_{+}=21$

Sum of negative rank $=T_{-}=34$

Hence $T=21$ as it is the smallest of the two values.

Using the hypothesis as in the previous case, for level of significance being

$(\alpha=0.05) t=8$ (Wilcoxon's table).

Stimce $(T$

t) we also conclude that both sets of values do not vary significantly from

themselves.

\section{RESULTS AND DISCUSSIONS}

The relationship between the feed grade and the concentration characteristics as computed from the model is shown on table 6 and thereafter depicted on figures 2 and 3.

Table 6:Concentration characteristics as computed from the model

\begin{tabular}{|l|l|l|l|l|l|l|l|l|l|l|}
\hline & 1988 & 1989 & 1990 & 1991 & 1992 & 1993 & 1994 & 1995 & 1996 & 1997 \\
$\begin{array}{l}\text { Conc. } \\
\text { Characteristics }\end{array}$ & & & & & & & & & & \\
\hline Feed grade $\left(\mathrm{F}_{\mathrm{g}}\right)$ & 40.95 & 38.68 & 37.88 & 36.44 & 36.45 & 36.44 & 35.01 & 34.95 & 34.42 & 34.19 \\
\hline Tailings Grade $\left(\mathrm{T}_{\mathrm{g}}\right)$ & 12.88 & 12.31 & 12.11 & 11.75 & 11.76 & 11.75 & 11.40 & 11.38 & 11.25 & 11.19 \\
\hline Recovery $\left(\mathrm{R}_{\mathrm{m}}\right)$ & 85.31 & 84.07 & 83.63 & 82.84 & 82.85 & 82.84 & 82.06 & 82.02 & 81.73 & 81.61 \\
\hline
\end{tabular}

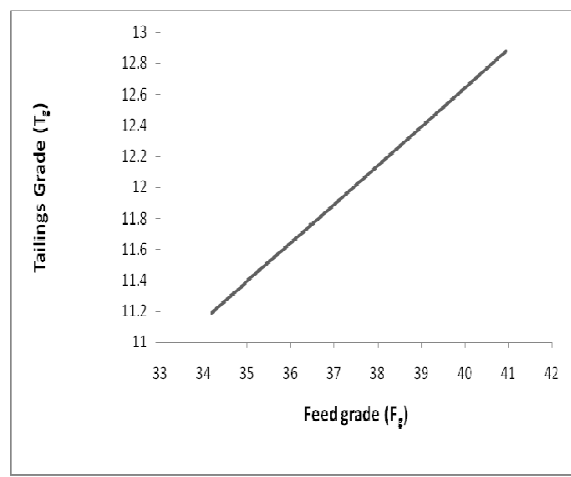

Fig. 2: Graph of Feed grade against computed Tailings grade

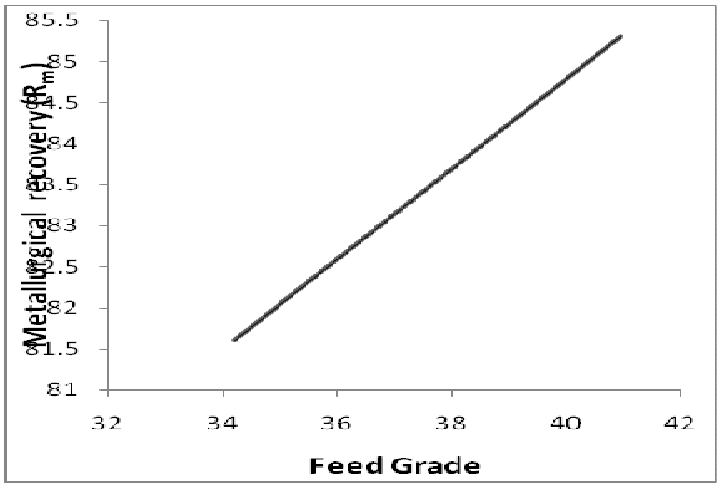

Fig. 3: Graph of Feed grade against computed Metallurgical recovery

Promerantsev. V.V (1990). Mineral Processing Analysis Nauka Publisher Moscow.

Agabalian U. A. (1994) Optimum Exploitation of Earth Resources: Theory and Practice. Published by Nedra Publishers Moscow p.62-65

Umunnakwe P.U. (1980) The Development of A New Mine, The Itakpe Case. Journal of AOMC.

Annual Report of Mines Laboratory, NIOMCO 1988 1997.

Gutep R. C. and Ovchinsky BV (1970) Elements of Numerical Modelling and Data Analysis. Published by Nauka Publishers, Moscow.

David A.T. Donohue (1983) Production Rate Decline Curve. Published by International Human Resources Development Corporation IHRDC Boston USA.

NIOMCProject Report; 1980, Vol. 2

\section{REFERENCES}

Arua A.I. (1997) Fundamentals of statistics, Publisher, Fijac Academic Press 